\title{
Bergerac - Les Libraires
}

$n^{\circ} 026064$

\section{Céline Lagarde-Cardona}

\section{(2) OpenEdition \\ 1 Journals}

Édition électronique

URL : https://journals.openedition.org/adlfi/16289

ISSN : 2114-0502

Éditeur

Ministère de la Culture

Référence électronique

Céline Lagarde-Cardona, «Bergerac - Les Libraires » [notice archéologique], ADLFI. Archéologie de la France - Informations [En ligne], Nouvelle-Aquitaine, mis en ligne le 10 février 2016, consulté le 21 septembre 2021. URL : http://journals.openedition.org/adlfi/16289

Ce document a été généré automatiquement le 21 septembre 2021.

(c) ministère de la Culture et de la Communication, CNRS 


\title{
Bergerac - Les Libraires
}

\author{
$n^{\circ} 026064$
}

\section{Céline Lagarde-Cardona}

Lien Atlas (MCC) :

http://atlas.patrimoines.culture.fr/atlas/trunk/index.php?

ap_theme=DOM_2.01.02\&ap_bbox $=0.431 ; 44.804 ; 0.545 ; 44.900$

1 Un diagnostic archéologique a été mené dans le cadre du projet de suppression du passage à niveau au lieu-dit les Libraires, par le service archéologique départemental de la Dordogne. Trente-quatre sondages ont été réalisés sur une surface de 2,6 hectares.

2 Le terrain se situe en basse terrasse de la rive droite de la Dordogne, au pied du plateau du Pécharmant. Il recoupe deux niveaux de terrasses alluviales qui se caractérisent chacune par la présence d'un replat topographique séparé par un talus.

3 La partie ouest présente un faciès sédimentaire d'épais dépôts sablo-limoneux recouvrant les graves de la nappe alluviale ; le contexte archéologique est négatif.

4 Dans la partie orientale, un faciès de dépôts alluviaux caractérise la présence de paléoméandres encaissés dans la basse terrasse. Des indices d'occupation ont été mis en évidence dans la séquence d'épandage colluvio-alluvial qui recouvre ces dépôts alluviaux. Plusieurs phases d'occupation sont représentées de manière inégale mais d'une manière générale, la densité de structures et de matériel reste faible :

- le Paléolithique supérieur n'est représenté que par une lame à crête en silex, probablement en position secondaire ;

- en bordure est du terrain d'emprise, un trou de poteau isolé et de rares pièces lithiques se rapportent à une occupation de la fin du Néolithique. Cet ensemble est à relier à un contexte local néolithique mis en évidence sur les sites des Galinoux, de Cablanc et du Pré Fagnou ;

- l'âge du Fer apparaît sous la forme de plusieurs structures fossoyées associées à du matériel de rejet de combustion. Des scories de fer mettent en évidence une activité métallurgique à proximité de ce secteur. Compte tenu de la faible documentation, l'attribution chronologique reste à préciser ; 
- une occupation attribuée au Bas Moyen Âge se compose d'une fosse et d'un espace enclos par un étroit fossé curviligne.

INDEX

Mots-clés : silex, scories, fer, fossé

operation Fouille préventive (FP)

Index géographique : Aquitaine, Dordogne (24), Bergerac

Index chronologique : Paléolithique supérieur, Néolithique, bas Moyen Âge, âge du Fer

\section{AUTEURS}

\section{CÉLINE LAGARDE-CARDONA}

COL 